\title{
Probability distributions of landslide volumes
}

\author{
M. T. Brunetti, F. Guzzetti, and M. Rossi \\ Consiglio Nazionale delle Ricerche, Istituto di Ricerca per la Protezione Idrogeologica, Perugia, via Madonna Alta 126, \\ 06128 Perugia, Italy
}

Received: 28 August 2008 - Revised: 26 February 2009 - Accepted: 26 February 2009 - Published: 11 March 2009

\begin{abstract}
We examine 19 datasets with measurements of landslide volume, $V_{L}$, for sub-aerial, submarine, and extraterrestrial mass movements. Individual datasets include from 17 to 1019 landslides of different types, including rock fall, rock slide, rock avalanche, soil slide, slide, and debris flow, with individual landslide volumes ranging over $10^{-4} \mathrm{~m}^{3} \leq V_{L} \leq 10^{13} \mathrm{~m}^{3}$. We determine the probability density of landslide volumes, $p\left(V_{L}\right)$, using kernel density estimation. Each landslide dataset exhibits heavy tailed (self-similar) behaviour for their frequency-size distributions, $p\left(V_{L}\right)$ as a function of $V_{L}$, for failures exceeding different threshold volumes, $V_{L}^{*}$, for each dataset. These non-cumulative heavy-tailed distributions for each dataset are negative power-laws, with exponents $1.0 \leq \beta \leq 1.9$, and averaging $\beta \approx 1.3$. The scaling behaviour of $V_{L}$ for the ensemble of the 19 datasets is over 17 orders of magnitude, and is independent of lithological characteristics, morphological settings, triggering mechanisms, length of period and extent of the area covered by the datasets, presence or lack of water in the failed materials, and magnitude of gravitational fields. We argue that the statistics of landslide volume is conditioned primarily on the geometrical properties of the slope or rock mass where failures occur. Differences in the values of the scaling exponents reflect the primary landslide types, with rock falls exhibiting a smaller scaling exponent $(1.1 \leq \beta \leq 1.4)$ than slides and soil slides $(1.5 \leq \beta \leq 1.9)$. We argue that the difference is a consequence of the disparity in the mechanics of rock falls and slides.
\end{abstract}

\section{Introduction}

Landslides are caused by meteorological and geophysical triggers, and by human actions. Despite landslides being frequent and widespread, the statistics of landslide size are

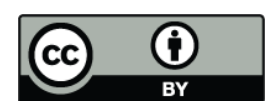

Correspondence to: M. T. Brunetti (mariateresa.brunetti@irpi.cnr.it) not fully determined and remain poorly understood (Stark and Hovius, 2001; Malamud et al., 2004b; Van Den Eeckhaut et al., 2007). In this work, we exploit 19 datasets listing measurements of landslide size to determine the probability density of landslide volume, $p\left(V_{L}\right)$. Results provide empirical evidence that the non-cumulative distribution of landslide volumes obeys a self-similar behaviour across 17 orders of magnitude. The finding has implications for landslide modelling (e.g., Hergarten and Neugebauer, 1998; Katz and Aharonov, 2006; Juanico et al., 2008), for landscape analysis (e.g., Hovius et al., 1997; Stark and Hovius, 2001; Malamud et al., 2004a; Korup, 2006; Guzzetti et al., 2008, 2009), for the determination of landslide hazard (Guzzetti et al., 2005, 2006), and as a starting point for the adoption of a quantitative scale of landslide magnitude, based on $V_{L}$ (Malamud et al., 2004b; Guzzetti et al., 2009).

We organize this paper by first giving a background to cumulative and non-cumulative frequency-size distribution formulas, and past studies that have examined the statistics of landslide volumes (Sect. 2). We follow this be a description of the 19 datasets used in this paper (Sect. 3), frequency-size analyses of the data (Sect. 4), discussion of the implications of our results (Sect. 5), and finally our conclusions (Sect. 6).

\section{Background}

To determine the statistics of landslide sizes (i.e., area or volume), investigators have used the cumulative or the noncumulative number-size distributions. Inspection of the literature (see below) reveals that, above a threshold, the cumulative distribution of large and very-large landslide volumes is generally well approximated by a negative power-law,

$$
N_{L}=r V_{L}^{-\alpha}
$$

where $N_{L}$ is the cumulative number of landslides, $V_{L}$ the landslide volume, $\alpha$ the cumulative power-law scaling exponent, and $r$ a constant. The corresponding

Published by Copernicus Publications on behalf of the European Geosciences Union and the American Geophysical Union. 
Table 1. Characteristics of datasets in the literature listing measurements of landslide volumes, $V_{L}$, for which the density distributions were estimated.

\begin{tabular}{|c|c|c|c|c|c|c|c|c|c|}
\hline Source ${ }^{\mathrm{a}}$ & Geographic area & $\begin{array}{l}\text { Number of } \\
\text { landslides }\end{array}$ & $\begin{array}{l}\text { Distribution } \\
\text { type }^{\mathrm{b}}\end{array}$ & Distribution $^{\mathrm{c}}$ & Volume range & Fit range & Units & $\begin{array}{l}\text { Landslide } \\
\text { type }^{\mathrm{d}}\end{array}$ & Trigger $^{\mathrm{e}}$ \\
\hline 1 & Japan & 800 & c & $N_{L}=10^{5.49} \cdot V_{L}^{-0.85}$ & $4 \times 10^{2}-10^{6}$ & $10^{3}-10^{6}$ & $\mathrm{~m}^{3}$ & $\mathrm{~m}$ & $\mathrm{r}$ \\
\hline 2 & Iceland & 224 & c & $N_{L} \propto V_{L}^{-\alpha}$ & $1 \times 10^{6}-4 \times 10^{7}$ & & $\mathrm{~m}^{3}$ & rs & $\mathrm{u}$ \\
\hline 3 & New Zealand & 42 & c & $N_{L} \propto V_{L}^{L}-\alpha$ & $1 \times 10^{6}-5 \times 10^{8}$ & & $\mathrm{~m}^{3}$ & $\mathrm{ra}$ & $\mathrm{u}$ \\
\hline $4,5,6$ & Alberta, Canada & 409 & $\mathrm{c}$ & $N_{L y} \propto V_{L}^{-0.72}$ & $1 \times 10^{-6}-1 \times 10^{1}$ & $10^{-1}-10^{1}$ & $\mathrm{~m}^{3}$ & $\mathrm{rf}$ & $\mathrm{u}$ \\
\hline 6 & Highway 99, British Columbia & 390 & $\mathrm{c}$ & $N_{L y}=0.77 \cdot V_{L}^{-0.43}$ & $1 \times 10^{-2}-8 \times 10^{4}$ & $1 \times 10^{0}-8 \times 10^{4}$ & $\mathrm{~m}^{3}$ & $\mathrm{rf}, \mathrm{rs}$ & $\mathrm{m}$ \\
\hline 6 & BCR line, British Columbia & 403 & $\mathrm{c}$ & $N_{L y}=0.12 \cdot V_{L}^{-0.40}$ & $1 \times 10^{-2}-2 \times 10^{4}$ & $1 \times 10^{0}-2 \times 10^{4}$ & $\mathrm{~m}^{3}$ & $\mathrm{rf}, \mathrm{rs}$ & $\mathrm{m}$ \\
\hline 6 & Highway 1, British Columbia & 226 & $\mathrm{c}$ & $N_{L y}=1.36 \cdot V_{L}^{L}-0.70$ & $1 \times 10^{-2}-2 \times 10^{4}$ & $1 \times 10^{0}-2 \times 10^{4}$ & $\mathrm{~m}^{3}$ & $\mathrm{rf}, \mathrm{rs}$ & $\mathrm{m}$ \\
\hline 6 & $\mathrm{CP}$ line, British Columbia & 918 & $\mathrm{c}$ & $N_{L y}=1.13 \cdot V_{L}^{-0.65}$ & $1 \times 10^{-2}-3 \times 10^{4}$ & $1 \times 10^{0}-3 \times 10^{4}$ & $\mathrm{~m}^{3}$ & rf, rs & $\mathrm{m}$ \\
\hline 7 & Hong Kong & 2811 & $\mathrm{c}$ & $N_{L}=2.33 \cdot V_{L}^{-0.79}$ & $1 \times 10^{-2}-1 \times 10^{5}$ & $3 \times 10^{0}-1 \times 10^{5}$ & $\mathrm{~m}^{3}$ & $\mathrm{rf}, \mathrm{m}$ & $\mathrm{r}$ \\
\hline 8 & Grenoble, France & 87 & $\mathrm{c}$ & $N_{L y}=4.2 \cdot V_{L}^{-0.41}$ & $5 \times 10^{-1}-1 \times 10^{6}$ & $5 \times 10^{1}-1 \times 10^{6}$ & $\mathrm{~m}^{3}$ & $\mathrm{rf}$ & $\mathrm{m}$ \\
\hline 8 & Arly gorges, France & 59 & $\mathrm{c}$ & $N_{L y}=8.5 \cdot V_{L}^{L}-0.45$ & $5 \times 10^{0}-1 \times 10^{4}$ & $2 \times 10^{1}-3 \times 10^{3}$ & $\mathrm{~m}^{3}$ & $\mathrm{rf}$ & $\mathrm{m}$ \\
\hline 8 & Yosemite, USA & 101 & $\mathrm{c}$ & $N_{L y}=4.5 \cdot V_{L}^{L}-0.46$ & $1 \times 10^{0}-1 \times 10^{6}$ & $5 \times 10^{1}-1 \times 10^{6}$ & $\mathrm{~m}^{3}$ & $\mathrm{rf}$ & $\mathrm{m}$ \\
\hline 9 & World wide & 142 & $\mathrm{c}$ & $N_{L y} \propto V_{J}^{-0.52}$ & $1 \times 10^{3}-2 \times 10^{10}$ & $3 \times 10^{7}-2 \times 10^{10}$ & $\mathrm{~m}^{3}$ & $\mathrm{rf}$ & $\mathrm{u}$ \\
\hline 9 & Mahaval, La Réunion & 370 & $\mathrm{c}$ & $N_{L y} \propto V_{L}^{-1.0}$ & $<9 \times 10^{6}$ & & $\mathrm{~m}^{3}$ & $\mathrm{rf}$ & $\mathrm{m}$ \\
\hline 10 & Storega, off shore Norway & $\approx 60$ & $\mathrm{c}$ & $N_{L}=29.6-14.2 \cdot \log V_{L}$ & $1 \times 10^{-2}-1 \times 10^{3}$ & $1 \times 10^{-2}-1 \times 10^{2}$ & $\mathrm{~km}^{3}$ & $\mathrm{sm}$ & $\mathrm{u}$ \\
\hline 11 & Queen Charlotte Islands, Canada & 475 & $\mathrm{nc}$ & $p\left(V_{L}\right) \propto V_{L}^{-1.87}$ & $\approx 1 \times 10^{2}-1.6 \times 10^{4}$ & $5 \times 10^{2}-1.6 \times 10^{4}$ & $\mathrm{~m}^{3}$ & $\mathrm{df}, \mathrm{ds} \dagger$ & $\mathrm{r}$ \\
\hline 11 & Queen Charlotte Islands, Canada & 140 & $\mathrm{nc}$ & $p\left(V_{L}\right) \propto V_{L}^{-2.94}$ & $\approx 1 \times 10^{2}-1.2 \times 10^{3}$ & $2 \times 10^{2}-1.2 \times 10^{3}$ & $\mathrm{~m}^{3}$ & df, ds $\doteqdot$ & $\mathrm{r}$ \\
\hline 12 & Yosemite, USA & 392 & $\mathrm{nc}$ & $f\left(V_{L}\right)=10 \cdot V_{L}^{-1.1}$ & $1 \times 10^{-1}-6 \times 10^{5}$ & $1 \times 10^{-1}-6 \times 10^{5}$ & $\mathrm{~m}^{3}$ & $\mathrm{rf}, \mathrm{rs}$ & $\mathrm{m}$ \\
\hline 13 & Umbria Marche, central Italy & 155 & $\mathrm{nc}$ & $f\left(V_{L}\right)=0.1 \cdot V_{L}^{-1.2}$ & $9.9 \times 10^{-5}-2.0 \times 10^{2}$ & $9.9 \times 10^{-5}-2.0 \times 10^{2}$ & $\mathrm{~m}^{3}$ & $\mathrm{rf}$ & $\mathrm{e}$ \\
\hline 13 & Balza Tagliata, Umbria, Italy & 62 & $\mathrm{nc}$ & $f\left(V_{L}\right)=0.1 \cdot V_{L}^{-1.2}$ & $8.1 \times 10^{-3}-1.3 \times 10^{2}$ & $8.1 \times 10^{-3}-1.3 \times 10^{2}$ & $\mathrm{~m}^{3}$ & rf & $\mathrm{e}$ \\
\hline 13 & Balza Tagliata, Umbria, Italy & 1696 & $\mathrm{nc}$ & $f\left(V_{L}\right)=0.01 \cdot V_{L}^{-1.6}$ & $2.4 \times 10^{-5}-5.4 \times 10^{1}$ & $2.4 \times 10^{-5}-5.4 \times 10^{1}$ & $\mathrm{~m}^{3}$ & $\mathrm{rf} *$ & $\mathrm{e}$ \\
\hline 14 & Multiple areas & & $\mathrm{nc}$ & $f\left(V_{L}\right)=2.34 \cdot V_{L}^{-1.07}$ & $10^{-12}-10^{-3}$ & & $\mathrm{~km}^{3}$ & $\mathrm{rf}$ & $\mathrm{m}$ \\
\hline 15 & Capilano watershed, Canada & 2984 & nc & $f\left(V_{L}\right) \propto V_{L}^{-\beta}, 1.1 \leq \beta \leq 3.6$ & $1 \times 10^{1}-2 \times 10^{-5}$ & & $\mathrm{~m}^{3}$ & ss & $\mathrm{m}$ \\
\hline
\end{tabular}

a 1, Fujii (1969); 2, Whalley et al. (1983); 3, Whitehouse and Griffiths (1983); 4, Gardner (1970); 5, Gardner (1983); 6, Hungr et al. (1999); 7, Dai and Lee (2001); 8, Dussauge-Peisser et al. (2002); 9, Dussauge et al. (2003); 10, Issler et al. (2005); 11, Martin et al. (2002); 12, Guzzetti et al. (2003); 13, Guzzetti et al. (2004); 14, Malamud et al. (2004b); 15, Brardinoni and Church (2004).

$\mathrm{b}$ c, cumulative distribution; nc, non-cumulative distribution.

${ }^{\mathrm{c}} N_{L}$, cumulative number; $N_{L y}$, cumulative number or frequency per year; $f\left(V_{L}\right)$, frequency density; $p\left(V_{L}\right)$, probability density.

$\mathrm{d}$ rf, rock fall; rs, rock slide; ra, rock avalanche; ss, soil slide; df, debris flow; sm, submarine; m, multiple; u, unknown; $\dagger$, primary failure; $\ddagger$, sidewall failure; *, rock fragments.

${ }^{\mathrm{e}} \mathrm{r}$, rainfall; e, earthquake; m, multiple events or triggers; $\mathrm{u}$, unknown.

non-cumulative number-volume distribution $N_{L}^{\prime}$ also follows a power-law,

$N_{L}^{\prime}=\frac{d N_{L}}{d V_{L}}=-\alpha r V_{L}^{-(\alpha+1)}=s V_{L}^{-\beta} \equiv f\left(V_{L}\right) \equiv N_{L T} p\left(V_{L}\right)$

with $d N_{L}$ the number of landslides in the volume interval $\left[V_{L} ; V_{L}+d V_{L}\right]$ (i.e. in a "bin" of size $d V_{L}$ ), $\beta$ the noncumulative scaling exponent, and $s$ a constant. Equation (2) further shows that the non-cumulative number-volume distribution, $N_{L}{ }^{\prime}$, is equivalent to the frequency density of $V_{L}$, $f\left(V_{L}\right)$. The corresponding probability density of $V_{L}, p\left(V_{L}\right)$, is obtained by dividing $f\left(V_{L}\right)$ by the total number of landslides, $N_{L T}$. For a non-cumulative power-law distribution with exponent $\beta>1$, the corresponding cumulative distribution, obtained by integration or summing, has exponent $\alpha=\beta-1$ (Guzzetti et al., 2002).

We now discuss past literature that has examined the frequency-volume distribution of landslides. A summary of these 15 studies is given in Table 1. In this literature review table, for each study, we have indicated geographic area, number of landslides considered, whether the authors used cumulative or non-cumulative frequency-volume statistics and over which range they were fitting the data, size distribution found, the landslide type in their studies (rock fall, rock slide, rock avalanche, soil slide, slide, debris flow, submarine landslide) and the trigger of the landslides (rainfall, earthquake).

Fujii (1969) was probably the first to investigate the statistics of landslide size. Studying an inventory of 800 landslides caused by heavy rainfall in Japan, he obtained a cumulative number-volume distribution that correlated with a power-law relation, $\alpha=0.85$ (Eq. 2). Whalley et al. (1983) examined data for 224 large rockslides in Iceland. Whitehouse and Griffiths (1983) studied 42 rock avalanche deposits in the central Southern Alps of New Zealand. The two datasets exhibited power-law scaling of the frequency of $V_{L}$, with a value for $\alpha$ not specifically given. Gardner (1983) investigated rock falls and rock slides in Alberta, Canada, and provided an exponential relationship for the frequency of $V_{L}$. Hungr et al. (1999) have given a cumulative 
frequency-volume distribution for 1937 rock falls and rock slides in south-western British Columbia, divided into four subareas, exhibiting negative power-laws with $\alpha=0.5 \pm 0.2$. Dai and Lee (2001) examined 2811 landslides, mostly rock falls, in Hong Kong in the period 1992-1997, and found that the cumulative frequency-volume distribution followed a negative power-law, with $\alpha=0.8$. Dussauge-Peisser et al. (2002) compiled rock fall inventories for the Grenoble area and for the Arly gorges, France, and determined that the cumulative frequency distributions of the rock fall volumes exhibited negative power-law behaviour with $\alpha=0.41$ and $\alpha=0.45$, respectively. Dussauge et al. (2003) studied a world-wide inventory of 142 rock falls, and an inventory of 370 instrumental measurements of rock fall failures at Mahaval, La Réunion, and established that the cumulative frequency-volume distributions were negative power-law functions, with $\alpha=0.52$ and $\alpha=1.0$, respectively. Issler et al. (2005) studied submarine debris flows in the Storega landslide area, off shore Norway, and found that the cumulative number-volume distribution was approximated by a logarithmic relationship, $N_{L}=29.6-14.2 \log V_{L}$, with $V_{L}$ in $\mathrm{km}^{3}$.

Martin et al. (2002) found that the non-cumulative probability density for the volume of shallow landslides in the Queen Charlotte Islands, British Columbia, correlated with a negative power-law relation, with $\beta=1.87$ for primary (open slope) failures, and $\beta=2.94$ for gully (sidewall) failures. Guzzetti et al. (2003) analyzed a catalogue of historical rock falls in Yosemite National Park, USA, compiled by Wieczorek et al. (1992), and determined that the noncumulative frequency density of rock fall volumes exhibited power-law scaling, with $\beta=1.1$. Guzzetti et al. (2004) examined two inventories of earthquake induced rock falls in the Umbria-Marche Apennines, Italy, and established that the non-cumulative frequency density of rock fall volumes obeyed power-law scaling, with $\beta=1.2$. Malamud et al. (2004b) re-examined the catalogues of rock falls available for the Yosemite area (Wieczorek et al., 1992), for the Grenoble area (Dussauge-Peisser et al., 2002), and for the Umbria region (Guzzetti et al., 2004), and gave a non-cumulative frequency density distribution for all three data sets, over twelve orders of magnitude, that was well approximated by a negative power-law, with $\beta=1.1$. Brardinoni and Church (2004), measured the volume of shallow landslides in the Capilano watershed, British Columbia, and gave non-cumulative frequency-volume relationships that followed power-law relations, with $\beta=2.7$ to 3.6.

Review of the literature reveals that the proposed empirical distributions of landslide volumes obey almost invariably a negative power-law scaling (Table 1). Variability exists in the exponent of the power-law tails of the distributions. Part of the variability is natural i.e., due to different landslide types and local morphological and lithological settings. However, part of the variability is fictitious, and caused by the different methods used to collect the data and to estimate the distributions (White et al., 2008).

\section{Available data}

For our own analyses, we used 19 datasets available in the literature with measurements of landslide volume, $V_{L}$. We summarize the characteristics of each of these datasets in Table 2. Of the available datasets, 17 list the volumes of subaerial landslides (A to O, Q to R, in Table 2), one lists submarine failures $(\mathrm{P})$, and one lists extraterrestrial mass movements (S). Multiple types of mass movements are considered, including rock fall, rock slide, rock avalanche, soil slide, slide, and debris flow (Cruden and Varnes, 1996). The number of landslides in each dataset varies from 17 (O) to 1019 $(\mathrm{J})$, and the volume of the individual landslides spans 17 orders of magnitude, from $1.0 \times 10^{-4} \mathrm{~m}^{3}$ (A) to $1.8 \times 10^{13} \mathrm{~m}^{3}$ (S). The techniques used to measure individual landslide volumes varies. For some datasets (e.g., A, B, C, D, O) individual landslide volumes were measured in the field. For other datasets (e.g., E, F, G, J, L, N) the landslide volume was obtained by multiplying landslide length, width, and depth measured in the field, on topographic maps, or from aerial photographs (e.g., Simonett, 1967; Rice et al., 1969; Rice and Foggin, 1971; Larsen and Torres-Sánchez, 1996, 1998; Baum et al., 2000; Barnard et al., 2001). For the other datasets, the technique used to measure $V_{L}$ is unknown.

Measurements of landslide volume are affected by various types of errors, which are difficult to quantify. For most datasets, the error associated with the measurement of $V_{L}$ is unknown. Based on geomorphological evidence and field experience, Guzzetti et al. (2009) argued that the error associated with the measurement of $V_{L}$ is within the same order of magnitude as the measured volume. For this work, we adopted a similar approach, and we attributed an uncertainty to the measurements of $V_{L}$ in each dataset, based chiefly on the landslide type and on information on the method used to obtain $V_{L}$ (Table 2). We assumed that the uncertainty depends primarily on the difficulty in estimating the landslide sub-surface geometry and depth. We divided the 19 datasets in three groups, and attributed to each group a level of uncertainty, expressed as a range $I$ of possible values for the true (unknown) landslide volume. Datasets listing landslide volumes measured in the field or using quantities (i.e., length, width, area) measured in the field or obtained through detailed analysis of aerial photographs, were attributed a range $I=\left[0.5 V_{L} ; 1.5 V_{L}\right]$, corresponding to an uncertainty of $50 \%$. Datasets reporting submarine or extraterrestrial landslides, or landslides for which no information was available on the method used to measure the landslide volume, were assigned a range $I=\left[0.2 V_{L} ; 5 V_{L}\right]$, corresponding to a factor of five uncertainty. Other datasets were attributed a range $I=\left[0.5 V_{L}\right.$; $2 V_{L}$ ], corresponding to a factor of two uncertainty. We acknowledge that the adopted classification is heuristic and somewhat subjective, but we maintain it provides a reasonable proxy for the error associated with the measurement of $V_{L}$. 
Table 2. Characteristics of 19 landslide datasets used in this study, listed in ascending order of minimum landslide volume. Last two columns show (i) the minimum landslide volume $V_{L}^{*}$ selected for the least-square linear fitting of the tail of the probability distribution, and (ii) the corresponding scaling exponent $\beta$ of the negative power-law fit.

\begin{tabular}{|c|c|c|c|c|c|c|c|c|c|c|c|c|c|}
\hline \multirow[t]{2}{*}{ ID } & \multirow[t]{2}{*}{ Source $^{\mathrm{a}}$} & \multirow[t]{2}{*}{ Dataset } & \multirow{2}{*}{$\begin{array}{c}\text { Number of } \\
\text { landslides, } N_{L T}\end{array}$} & \multicolumn{2}{|c|}{ Range of $V_{L}\left(\mathrm{~m}^{3}\right)$} & \multicolumn{2}{|c|}{$I^{\mathrm{b}}$} & \multirow{2}{*}{$\begin{array}{l}\text { Landslide } \\
\text { type }^{c}\end{array}$} & \multirow{2}{*}{$\begin{array}{l}\text { Rock } \\
\text { type }^{d}\end{array}$} & \multirow[t]{2}{*}{ Trigger $^{\mathrm{e}}$} & \multirow[t]{2}{*}{ Age or period ${ }^{f}$} & \multirow{2}{*}{$\begin{array}{c}\text { Threshold } \\
V_{L}^{*}\left(\mathrm{~m}^{3}\right)\end{array}$} & \multirow{2}{*}{$\begin{array}{l}\text { Slope } \\
\beta \pm \varepsilon^{\mathrm{g}}\end{array}$} \\
\hline & & & & $\min$ & $\max$ & $\min$ & $\max$ & & & & & & \\
\hline A & 1 & Umbria-Marche, central Italy & 133 & $1.0 \times 10^{-4}$ & $2.0 \times 10^{2}$ & $0.5 V_{L}$ & $1.5 V_{L}$ & $\mathrm{rf}, \mathrm{rs}$ & $\mathrm{s}$ & e & 29 Sep-14 Oct 1997 & $1.0 \times 10^{-1}$ & $1.3 \pm 0.0$ \\
\hline $\mathrm{B}$ & 1,2 & Balza Tagliata, Umbria, Italy & 62 & $4.0 \times 10^{-3}$ & $1.3 \times 10^{2}$ & $0.5 V_{L}$ & $1.5 V_{L}$ & $\mathrm{rf}$ & $\mathrm{s}$ & $\mathrm{e}$ & 14 Oct 1997 & $1.0 \times 10^{-1}$ & $1.4 \pm 0.0$ \\
\hline $\mathrm{C}$ & 3,4 & Grenoble, France & 105 & $3.0 \times 10^{-2}$ & $5.0 \times 10^{8}$ & $0.5 V_{L}$ & $1.5 V_{L}$ & $\mathrm{rf}$ & $\mathrm{s}$ & $\mathrm{m}$ & 1935 to 1995 & $1.0 \times 10^{1}$ & $1.2 \pm 0.0$ \\
\hline $\mathrm{D}$ & 5 & Yosemite, USA & 379 & $5.0 \times 10^{-2}$ & $1.1 \times 10^{7}$ & $0.5 V_{L}$ & $1.5 V_{L}$ & $\mathrm{rf}, \mathrm{rs}$ & $\mathrm{i}$ & $\mathrm{m}$ & 1867 to 2002 & $1.0 \times 10^{1}$ & $1.3 \pm 0.0$ \\
\hline $\mathrm{E}$ & 6 & New Guinea & 207 & $3.4 \times 10^{-1}$ & $1.4 \times 10^{6}$ & $0.5 V_{L}$ & $2 V_{L}$ & sl & $\mathrm{m}$ & $\mathrm{m}$ & $\mathrm{m}$ & $1.0 \times 10^{2}$ & $1.2 \pm 0.0$ \\
\hline $\mathrm{F}$ & 7 & Himalaya, India & 338 & $5.0 \times 10^{-1}$ & $4.0 \times 10^{5}$ & $0.5 V_{L}$ & $2 V_{L}$ & $\mathrm{~m}$ & $\mathrm{~m}$ & $\mathrm{~m}$ & $\mathrm{~m}$ & $1.0 \times 10^{2}$ & $1.5 \pm 0.0$ \\
\hline $\mathrm{G}$ & 8,9 & Southern California, USA & 66 & $8.0 \times 10^{-1}$ & $8.5 \times 10^{2}$ & $0.5 V_{L}$ & $1.5 V_{L}$ & ss, df & $\mathrm{m}$ & $\mathrm{r}$ & 1965 to 1969 & $3.2 \times 10^{1}$ & $1.6 \pm 0.1$ \\
\hline $\mathrm{H}$ & 10 & AVI archive, Italy & 916 & $1.0 \times 10^{0}$ & $6.0 \times 10^{8}$ & $0.5 V_{L}$ & $2 V_{L}$ & $\mathrm{~m}$ & $\mathrm{~m}$ & $\mathrm{~m}$ & 1900 to 2000 & $1.0 \times 10^{3}$ & $1.2 \pm 0.0$ \\
\hline I & 3,4 & Arly gorges, France & 25 & $5.0 \times 10^{0}$ & $1.0 \times 10^{4}$ & $0.5 V_{L}$ & $1.5 V_{L}$ & $\mathrm{rf}$ & $\mathrm{s}, \mathrm{p}$ & $\mathrm{m}$ & 1954 to 1976 & $1.0 \times 10^{2}$ & $1.2 \pm 0.1$ \\
\hline $\mathrm{J}$ & 11,12 & Puerto Rico, USA & 1019 & $5.3 \times 10^{0}$ & $3.7 \times 10^{4}$ & $0.5 V_{L}$ & $1.5 V_{L}$ & ss, df & $\mathrm{v}$ & $\mathrm{r}$ & $\sim 1950$ to 1990 & $1.0 \times 10^{2}$ & $1.9 \pm 0.0$ \\
\hline $\mathrm{K}$ & 13,14 & Debris flow & 46 & $1.0 \times 10^{1}$ & $3.8 \times 10^{9}$ & $0.5 V_{L}$ & $2 V_{L}$ & df & $\mathrm{u}$ & $\mathrm{r}$ & $\mathrm{m}$ & $1.0 \times 10^{7}$ & $1.3 \pm 0.0$ \\
\hline $\mathrm{L}$ & p.c. & Tanaro valley, Northern Italy & 100 & $2.4 \times 10^{1}$ & $8.4 \times 10^{3}$ & $0.5 V_{L}$ & $1.5 V_{L}$ & $\mathrm{sl}$ & $\mathrm{s}$ & $\mathrm{r}$ & Nov 1994 & $3.2 \times 10^{2}$ & $1.8 \pm 0.1$ \\
\hline M & 15 & World slides & 404 & $7.5 \times 10^{1}$ & $2.9 \times 10^{10}$ & $0.2 V_{L}$ & $5 V_{L}$ & $\mathrm{~m}$ & $\mathrm{~m}$ & $\mathrm{~m}$ & $\mathrm{~m}$ & $1.0 \times 10^{7}$ & $1.5 \pm 0.1$ \\
\hline $\mathrm{N}$ & 16 & Washington, USA & 20 & $7.6 \times 10^{1}$ & $1.1 \times 10^{6}$ & $0.5 V_{L}$ & $2 V_{L}$ & ss, df & $\mathrm{s}$ & $\mathrm{r}$ & $\mathrm{u}$ & $1.0 \times 10^{3}$ & $1.3 \pm 0.0$ \\
\hline $\mathrm{O}$ & 17 & Peat slides, Shetland Is., UK & 17 & $2.3 \times 10^{3}$ & $5.9 \times 10^{4}$ & $0.5 V_{L}$ & $1.5 V_{L}$ & ss & $\mathrm{s}$ & $\mathrm{m}$ & $\mathrm{u}$ & $6.3 \times 10^{3}$ & $1.6 \pm 0.1$ \\
\hline $\mathrm{P}$ & 18,19 & Submarine & 43 & $6.0 \times 10^{3}$ & $5.0 \times 10^{12}$ & $0.2 V_{L}$ & $5 V_{L}$ & $\mathrm{sm}$ & $\mathrm{s}$ & $\mathrm{u}$ & $\mathrm{u}$ & $1.0 \times 10^{10}$ & $1.0 \pm 0.1$ \\
\hline Q & 19,20 & Non volcanic & 153 & $3.0 \times 10^{4}$ & $2.1 \times 10^{10}$ & $0.2 V_{L}$ & $5 V_{L}$ & df, ra & $\mathrm{m}$ & $\mathrm{r}$ & $\mathrm{u}$ & $1.0 \times 10^{7}$ & $1.1 \pm 0.0$ \\
\hline $\mathrm{R}$ & 19,21 & Volcanic & 55 & $1.8 \times 10^{5}$ & $2.8 \times 10^{10}$ & $0.2 V_{L}$ & $5 V_{L}$ & $\mathrm{df}, \mathrm{lh}$ & $\mathrm{v}$ & $\mathrm{m}$ & $\mathrm{u}$ & $1.0 \times 10^{9}$ & $1.1 \pm 0.1$ \\
\hline S & 19,22 & Mars-Moon & 28 & $2.0 \times 10^{8}$ & $1.8 \times 10^{13}$ & $0.2 V_{L}$ & $5 V_{L}$ & $\mathrm{ra}, \mathrm{rs}$ & $\mathrm{u}$ & $\mathrm{u}$ & $\mathrm{u}$ & $1.0 \times 10^{10}$ & $1.0 \pm 0.0$ \\
\hline
\end{tabular}

a 1, Antonini et al. (2002); 2, Guzzetti et al. (2004); 3, Dussauge-Peisser et al. (2002); 4, Dussauge et al. (2003); 5, Wieczorek et al. (1992); 6, Simonett (1967); 7, Barnard et al. (2001); 8, Rice et al. (1969); 9, Rice and Foggin (1971); 10, Guzzetti and Tonelli (2004); 11, Larsen and Torres-Sánchez (1996); 12, Larsen and Torres-Sánchez (1998); 13, Iverson (1997); 14, Iverson et al. (1998); 15, Guzzetti et al. (2009); 16, Baum et al. (2000); 17, Dykes and Warburton (2008); 18, Hampton et al. (1996); 19, Legros (2002); 20, Erismann and Abele (2001); 21, Hayashi and Self (1992); 22, McEwen (1989); p.c., P. Aleotti, personal communication to FG (2002).

$\mathrm{b}$ uncertainty, expressed as a range of possible values for the true (unknown) landslide volume; see text for explanation.

${ }^{\mathrm{c}}$ rf, rock fall; rs, rock slide; ra, rock avalanche; ss, soil slide; sl, slide; df, debris flow; lh, lahar; sm, submarine; m, multiple; u, unknown.

$\mathrm{d}_{\mathrm{i}}$, intrusive; p, metamorphic; s, sedimentary; v, volcanic; m, multiple events or triggers; u, unknown.

e r, rainfall; e, earthquake; m, multiple; u, unknown.

${ }^{\mathrm{f}} \mathrm{m}$, multiple dates or periods; $\mathrm{u}$, unknown date or period.

g see Fig. $4 ; \varepsilon=0.0$ indicates that the error $\varepsilon$ is smaller than 0.05 , and $\varepsilon=0.1$ indicates that the error is $0.05 \leq \varepsilon \leq 0.09$.

No rigorous definition exists for the completeness of a landslide dataset (Malamud et al., 2004b; Guzzetti et al., 2009). In this work, a complete dataset is a dataset for which it is reasonable to assume that all landslides within the range of volume allowed by the adopted measuring technique were measured. Completeness of the 19 studied datasets depends on the measurement technique. Datasets listing landslides caused by a single triggering event (Malamud et al., 2004b), or obtained through direct field survey (e.g., A, B, C, G, I, J, L, O), are considered, to a large extent, complete. The Yosemite dataset (D), obtained through a systematic and long-term record of rock falls and rock slides covering several years (Wieczorek et al., 1992), is considered substantially complete for the period 1980-2002, and incomplete for the previous period (1867-1979) (Guzzetti et al., 2003). Other datasets (e.g., E, F, H, K, M, N, P, Q, R, S) are incomplete, and their degree of completeness remains undetermined.

\section{Data analysis}

We analyzed the 19 landslide datasets individually to get estimates of the probability density of landslide volume $p\left(V_{L}\right)$, and to establish similarities and differences between the probability distributions. To minimize problems related to the use of different statistical methods for the estimation of the probability density of $V_{L}$, we selected a single method and applied it to all the available datasets.

Inspection of the individual histograms obtained from the raw data reveals that the non-cumulative distributions of $V_{L}$ exhibit many more small values than large ones, and appear (even with some bins with no values) to decay as a heavytail. An example for Umbria, Italy (dataset B) is shown in Fig. 1. Heavy-tailed data are commonly evaluated on logarithmic scales (e.g., Newman, 2005; White et al., 2008). Hence, we transformed the $V_{L}$ measurements taking the logarithm (base 10) of $V_{L}$, and obtained an ensemble of datasets with $-4.0 \leq \log V_{L} \leq 13.3$. To estimate the probability density of $\log V_{L}, p\left(\log V_{L}\right)$, we adopted kernel density estimation (KDE) (Silverman, 1986; Scott, 1992; Venables and Ripley, 2002). KDE replaces each value (in our case, each $\log V_{L}$ 

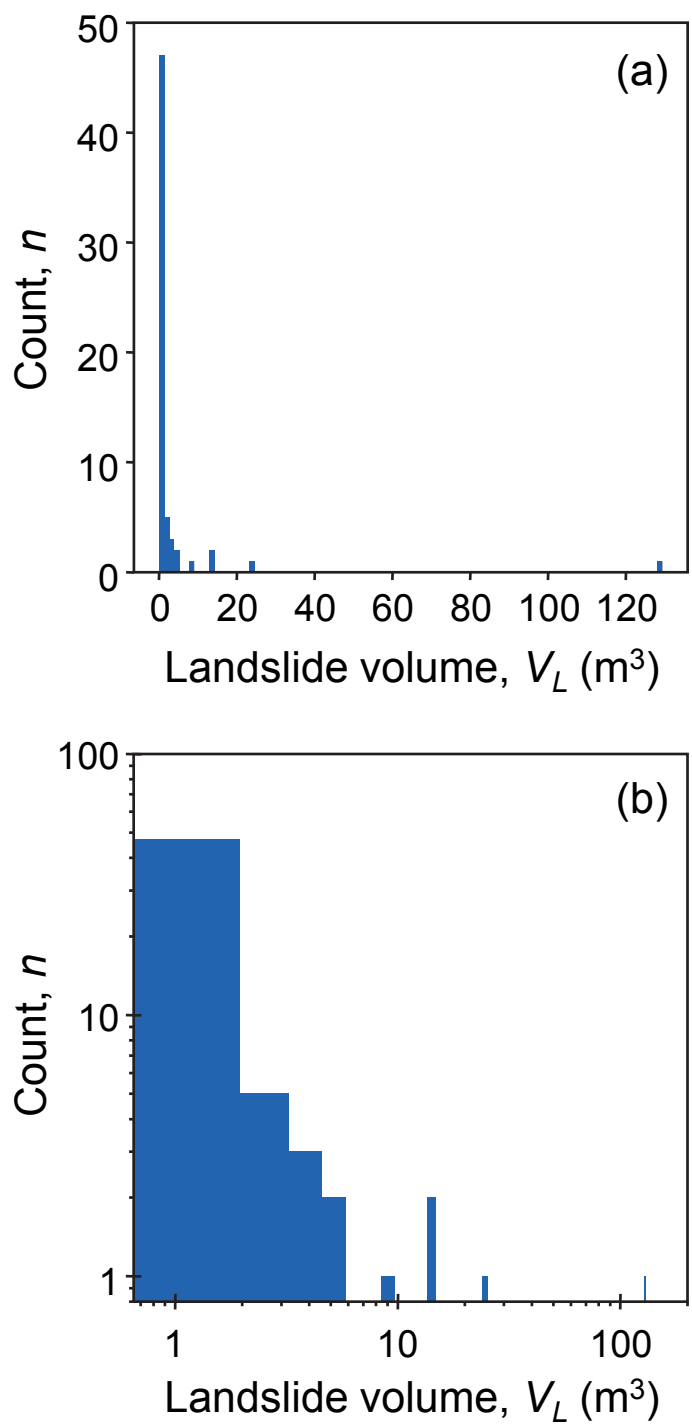

Fig. 1. Histograms show the number of landslides, $n$, as a function of landslide volume, $V_{L}$, for the Balza Tagliata dataset listing $N_{L T}=62$ earthquake induced rock falls in Umbria, central Italy (B in Table 2). Upper panel (a) shows count and volume in linear coordinates. Lower panel (b) shows count and volume in logarithmic coordinates.

measurement) with an associated kernel function, characterized by a given shape and bandwidth. We experimented with different kernel functions (i.e., Gaussian, triangular, rectangular) and bandwidths, and obtained optimally smoothed curves using a Gaussian kernel, with bandwidth (standard deviation) in the range between 0.3 and 0.5 , depending on the dataset. KDE was performed using the "density" function in the R software for statistical computing, release 2.6.2 (http://www.r-project.org/). The "density" algorithm distributed the mass of the empirical distribution on a regular grid of $n=10000$ points, used a fast Fourier transform to convolve the approximation with a discrete version of the kernel,

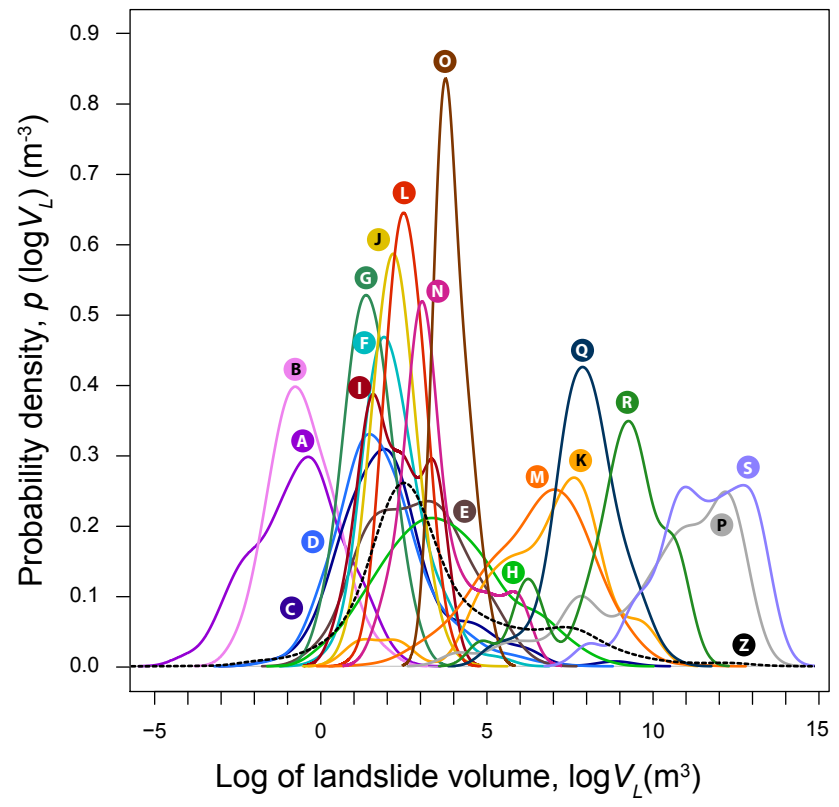

Fig. 2. Probability density of the logarithm of landslide volume $p\left(\log V_{L}\right)$ as a function of $\log V_{L}$, shown in linear coordinates. Probability densities were obtained through kernel density estimation. Letters A to S refer to dataset ID in Table 2. Letter Z refers to all dataset landslide volumes combined into one dataset (dashed black line).

and evaluated the density at selected bins through linear approximation (Silverman, 1986; Venables and Ripley, 2002).

Results of KDE are shown in Fig. 2 for the 19 considered datasets (A-S), and for an additional dataset (Z, dashed black line) that encompasses all the available $V_{L}$ measurements (4116 data). The inspection of Fig. 2 reveals (i) that several of the shown probability density distributions, obtained through KDE, are approaching symmetrical shapes, and (ii) that the probability density for the cumulative dataset $\mathrm{Z}$ has considerably longer tails. The latter is the result of the limited number of data for very small and very large landslides, i.e., for small and for $\operatorname{large} \log V_{L}$ values.

In Fig. 2, the individual probability densities, $p\left(\log V_{L}\right)$, are smoother than the corresponding histograms, and satisfy the normalization condition:

$\sum_{i=1}^{n} p_{i}\left(\log V_{L}\right)\left[\left(\log V_{L}\right)_{i+1}-\left(\log V_{L}\right)_{i}\right]=1$,

where $n=10000$, and $p_{i}\left(\log V_{L}\right)$ is the probability density for the $i$-th bin. Since we are interested in the probability density of $V_{L}, p\left(V_{L}\right)$, we transformed $p\left(\log V_{L}\right)$. The probability density $p\left(V_{L}\right)$ has to satisfy the same normalization condition:

$\sum_{i=1}^{n} p_{i}\left(V_{L}\right)\left[\left(V_{L}\right)_{i+1}-\left(V_{L}\right)_{i}\right]=1$ 


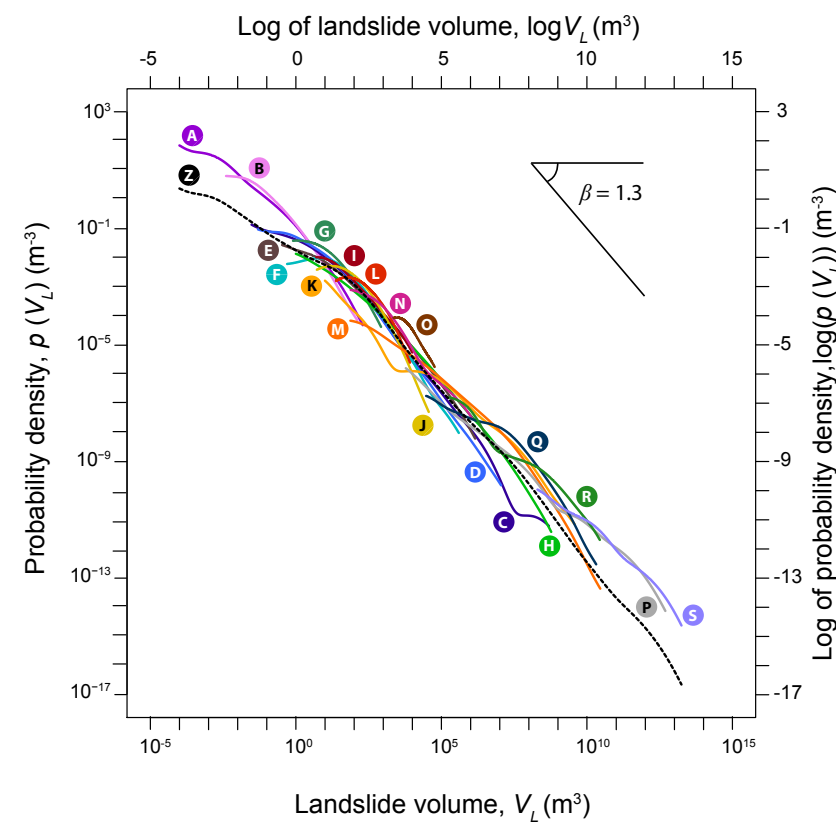

Fig. 3. Probability densities of landslide volumes, $p\left(V_{L}\right)$, as a function of $V_{L}$, shown in logarithmic coordinates (bottom and left axes). The same plot shows the logarithm of the probability density $\log \left(p\left(V_{L}\right)\right)$ as a function of $\log \left(V_{L}\right)$ in linear coordinates (top and right axes). Letters A to $\mathrm{S}$ refer to dataset ID in Table 2. Letter $\mathrm{Z}$ refers to all dataset landslide volumes combined into one dataset.

Considering Eqs. (3) and (4), we obtained:

$p_{i}\left(V_{L}\right)=\frac{p_{i}\left(\log V_{L}\right)\left[\left(\log V_{L}\right)_{i+1}-\left(\log V_{L}\right)_{i}\right]}{\left(V_{L}\right)_{i+1}-\left(V_{L}\right)_{i}}$

where $p_{i}\left(V_{L}\right)$ is the probability density of $V_{L}$ for the $i$-th bin. Results of the transformation, $p\left(V_{L}\right)$ as a function of $V_{L}$, are shown in Fig. 3 using logarithmic coordinates.

In Fig. 3, we observe that for volumes in the range $10^{1} \mathrm{~m}^{3} \leq V_{L} \leq 10^{9} \mathrm{~m}^{3}$, the probability densities $p\left(V_{L}\right)$ for dataset $Z$ (i.e. all data combined) obeys the general trend outlined by the ensemble of the probability density estimates obtained for the 19 individual datasets. This general trend tends towards a negative power-law with exponent $\beta \approx 1.3$. However, for very small $\left(V_{L}<10^{1} \mathrm{~m}^{3}\right)$ and for very large $\left(V_{L}>10^{9} \mathrm{~m}^{3}\right)$ landslides, the probability densities for dataset $\mathrm{Z}$ underestimates (i.e., are lower than) the densities obtained for individual datasets. This is a consequence of the shape of the density estimation for dataset Z (see Fig. 2), which is conditioned by the comparatively low number of $V_{L}$ measurements for very small and very large landslides in the cumulative dataset.

To better quantify the differences in the scaling of the tails of the probability densities, we obtained fits of the tails of the individual distributions, for $V_{L}$ greater than a threshold volume $V_{L}^{*}$ (Table 2). $V_{L}^{*}$ was selected for each dataset through visual inspection. To account for problems associated with the fitting of data spanning multiple orders of mag-

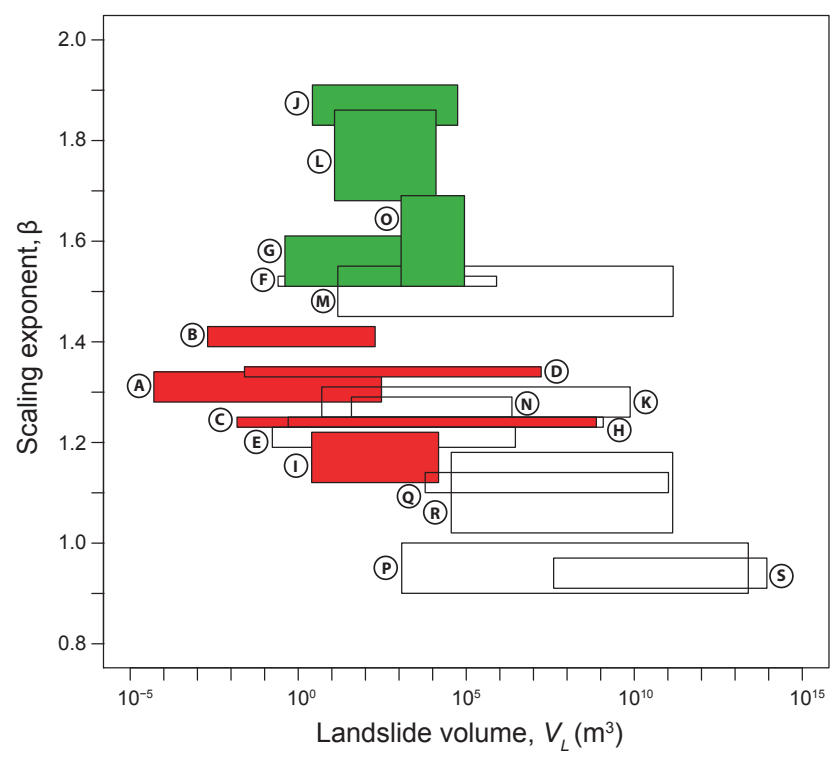

Fig. 4. Results of 100 simulations for each individual landslide dataset $\mathrm{A}$ to $\mathrm{S}$, that take into account the uncertainty on landslide volumes $V_{L}$ (see Table 2, and text). For each individual dataset, a rectangle shows: (i) (x-axis) the range of landslide volumes $V_{L}$, taking into consideration the range $I$ of possible values for the true (unknown) landslide volume; (ii) (y-axis) mean of the scaling exponents $\beta$ of the power-law tail for the 100 simulations, with the vertical height of the rectangle representing the standard deviation of the $\beta$ for those simulations. Colours show different landslide types: red for rock falls and rock slides, green for slides and soil slides, and white for other landslide types. Letters A to S refer to dataset ID in Table 2.

nitude (e.g., the least square minimization criteria may not work), $V_{L}$ and $p\left(V_{L}\right)$ were log-transformed (upper x-axis and right $y$-axis in Fig. 3). A straight line was fitted to the log-transformed data, which is entirely equivalent to a negative power-law $p\left(V_{L}\right) \propto V_{L}^{-\beta}$ (Eq. 2).

To account for the estimated error associated with the measurement of $V_{L}$ (Table 2), for each empirical dataset we constructed 100 synthetic datasets, each obtained by substituting the individual empirical measurements of $V_{L}$, with corresponding synthetic values, $V_{S}$. Each synthetic $V_{S}$ value was obtained by randomly sampling from a uniform distribution spanning a volume range $I$, determined by the corresponding $V_{L}$ measurement (Table 2). Power laws were fitted to the individual synthetic datasets, and statistics for the scaling exponents $\beta$ were determined (Table 2).

Figure 4 summarizes the results. For each landslide dataset, the range of landslide volumes $V_{L}$, including the estimated uncertainty, is shown along the x-axis. The corresponding variation of the scaling exponent $\beta$ for each dataset (i.e., one standard deviation centred on the mean value), is shown along the $y$-axis. For substantially complete datasets, $\beta$ is related to the landslide type. Rock falls and rock slides (A, B, C, D, I) exhibit lower scaling exponents $(1.1 \leq \beta \leq 1.4)$ 
than slides and soil slides (G, J, L, O) $(1.5 \leq \beta \leq 1.9)$. This is an indication that the relative proportion of large landslides is larger for rock falls, and smaller for slides. We attribute the difference to a disparity in the mechanics of rock falls and slides (Malanud et al., 2004b).

\section{Discussion}

Inspection of the 19 non-cumulative probability distributions of landslide volume obtained for the individual datasets reveals significant similarities and some differences (Fig. 3). Each individual dataset exhibits a distinct self-similar behaviour of $p\left(V_{L}\right)$ as a function of $V_{L}$, for failures exceeding a threshold size, $V_{L}^{*}$ (Table 2). The tails of the distributions are reasonably well approximated by negative power-laws, with $1.0 \leq \beta \leq 1.9$, average of $\beta \approx 1.3$, median 1.3, and standard deviation 0.3 (Table 2, Fig. 4). The scatter in the exponents of the tails of the probability distributions is more limited compared to the spread of the scaling exponents reported in the literature (Table 1). We attribute the reduced scatter to the technique adopted to obtain the probability density of $V_{L}$ and to fit power-laws to the (heavy) tails of the distributions.

Scatter in the value of the scaling exponents has multiple reasons, including: (i) different landslide types, that reflect different failure mechanisms (Cruden and Varnes, 1996), (ii) the natural variability inherent to landslide phenomena, and (iii) the number, quality, and completeness of the single datasets (Stark and Hovius, 2001; Guzzetti et al., 2002; Malamud et al., 2004b; Van Den Eeckhaut et al., 2007). The scaling of the power-law fits are independent of time, and of the period covered by the individual datasets that range (where known) from tens of seconds for earthquake-induced landslides $\left(\sim 10^{1} \mathrm{~s}, \mathrm{~B}\right)$, to a few hours for rainfall-induced landslides $\left(\sim 10^{4} \mathrm{~s}, \mathrm{~L}\right)$, to multiple decades $\left(\sim 10^{9} \mathrm{~s}, \mathrm{C}, \mathrm{D}, \mathrm{G}\right.$, H, I, J) (Table 2).

Some dataset (e.g., A, G, N, P) exhibit a deviation of the tail from the power-law behaviour, for the largest landslides in each dataset. For these datasets, the power-law fit overestimates the probability density, i.e. the empirical density is lower than the density modelled by the power-law fit. The behaviour has been observed for other natural hazards, including earthquakes (Turcotte, 1997). For landslides, it can be the result of: (i) under-sampling of the largest events e.g., because of the lack of data, or because the temporal span of a dataset is small compared to the frequency of large (rare) events, and (ii) geometrical constrains, e.g., a landslide cannot be larger than the slope where the failure occurs (Guzzetti et al., 2002).

A few datasets (e.g., F, G, J, L) exhibit a "rollover" of the probability densities for small $V_{L}$. This is similar to the "rollover" identified in the frequency and probability density functions of landslide areas (e.g., Pelletier et al., 1997; Stark and Hovius, 2001; Guzzetti et al., 2002; Brardinoni and Church, 2004; Malamud et al., 2004b; Van Den Eeckhaut et al., 2007). The "rollover" can be the result of under-sampling of the smallest landslides (Stark and Hovius, 2001), or a geomorphological (physical) property of the landslides, marking a change in the dominant processes that contribute to landslide formation and initiation (Guzzetti et al., 2002, 2008; Katz and Aharonov, 2006; Malamud et al., 2004b). Datasets showing a rollover contain landslides predominantly of the slide type, whereas rock falls do not exhibit a rollover. We attribute the difference to different failure mechanisms for the two landslide types (Malamud et al., 2004b).

Small datasets with $n \leq 55$ (I, K, N, O, P, R, S) show multiple deviations of the probability density from the power-law fit. We attribute the irregularities in the density functions for these datasets to the reduced size of the datasets, and to (partial) failure of the kernel density estimation to capture the landslide density.

In Fig. 3, the position of the individual probability density estimates is influenced by: (i) the range of $V_{L}$, that controls the placing along the $\mathrm{x}$-axis, (ii) the scaling of the distribution, which is similar for most of the datasets, and (iii) the normalization condition, expressed by Eq. (4). Location of the distributions along the $\mathrm{x}$-axis or the $\mathrm{y}$-axis is not influenced by the number of measurements in the datasets. Inspection of Fig. 3 reveals that the ensemble of the density functions clusters around a trending line that follows a negative power-law with a scaling exponent $\beta \approx 1.3$, across 17 orders of magnitude, $10^{-4} \mathrm{~m}^{3} \leq V_{L} \leq 10^{13} \mathrm{~m}^{3}$. The finding indicates a self-similar (fractal) (Turcotte, 1997; Turcotte et al., 2002; Cello and Malamud, 2006) behaviour of $p\left(V_{L}\right)$ as a function of $V_{L}$, over a very large range of volumes. This is in spite of lithological characteristics, morphological settings, triggering mechanisms, length of period and extent of the area covered by the datasets, presence or lack of water in the failed soils and rocks, and intensity of gravitational fields for extraterrestrial landslides (S) (Table 2). The scaling behaviour is the result of natural processes that control landslide volumes, and not an artefact introduced by the technique used to collect the samples, by the methods used to measure landslide volumes, or by the number of data in the individual datasets.

Further inspection of Fig. 3 reveals that the scaling of the distributions covering small (e.g., A, B), or medium (e.g., I, J), or large (e.g., P, S) landslides is rather similar. This is an indication that landslides of all sizes (in the range $10^{-4} \mathrm{~m}^{3} \leq V_{L} \leq 10^{13} \mathrm{~m}^{3}$ ) belong essentially to the same underlying frequency-size distribution. In other words, for landslide volumes the largest ("extreme") failures pertain to the same distribution as the other landslides. This finding is important because it allows using a range of $V_{L}$ for which datasets are most abundant, of higher quality, or more complete, to infer the scaling behaviour for other ranges of $V_{L}$ for which data are limited, and of poor or of uncertain quality. The fact that the 19 datasets individually cover only a reduced portion of the entire range of $V_{L}$ measurements is an indication that single datasets are bounded by geometrical or 
geomorphological limits. As discussed above, the reduced number of small landslides in a dataset is the result of a sampling problem, or a change in the process that initiates the landslides (Pelletier et al., 1997; Guzzetti et al., 2002; Malamud et al., 2004b; Katz and Aharonov, 2006). Conversely, the largest landslides in a dataset provide indication on the largest slope failure that can be caused by an individual trigger of given magnitude in an area (e.g., B in Table 2), or the largest slope failure that can form in a given landscape (Guzzetti et al., 2002, 2008).

We suggest that the distinct self-similar scaling behaviour of landslide volumes across several orders of magnitude is conditioned primarily on the geometrical properties of the system (i.e., slope or rock mass), where slope failures occur, and subordinately on the environmental (e.g., morphological, lithological, geological, meteorological, climatic) conditions that characterize the system. In other words, the statistics of $V_{L}$ is controlled by the geometrical scaling (spacing, length, persistence) of the discontinuities (e.g., bedding, lamination, schistosity, fracture, cleavage, joint, fault) that control the location and initial volume of the slope failures (Katz and Aharonov, 2006). This is confirmed by the fact that rock falls and rock slides have lower scaling exponents $(1.1 \leq \beta \leq 1.4)$ than slides and soil slides $(1.5 \leq \beta \leq 1.9)$, a consequence of the different mechanics of the two types of mass movements (Cruden and Varnes, 1996).

Our finding represents an advancement in the understanding of the statistics of landslides (Stark and Hovius, 2001; Malamud et al., 2004b; Van Den Eeckhaut et al., 2007) that can be used to confront physical (Katz and Aharonov, 2006) and computer (Hergarten and Neugebauer, 1998, Juanico et al., 2008) models of landslide sizes. The scale-invariant behaviour of landslide volume can prove useful to model erosion rates and sediment fluxes in landscapes dominated by mass-wasting processes (Hovius et al., 1997; Stark and Hovius, 2001; Malamud et al., 2004a; Korup, 2006; Guzzetti et al., 2008, 2009), where more detailed information is not available. The statistics of $V_{L}$ are also important for landslide hazard assessment (Guzzetti et al., 2005, 2006), and specifically for modelling rock fall hazard (Guzzetti et al., 2003, 2004). Lastly, we anticipate our results to contribute to establish a physically-based magnitude scale for landslide events, based on landslide volume (Malamud et al., 2004b; Guzzetti et al., 2009).

\section{Conclusions}

Through kernel density estimation, we obtained the probability densities of landslide volumes for 19 datasets, which included sub-aerial, submarine and extraterrestrial mass movements. Analysis of the probability densities, $p\left(V_{L}\right)$, indicates that each dataset exhibits negative power-law scaling of $p\left(V_{L}\right)$ as a function of $V_{L}$, for landslides exceeding a threshold volume. The ensemble of the probability density esti- mates obtained for the individual datasets follows a negative power-law (scale invariant trend) with exponent $\beta \approx 1.3$, in the range $10^{-4} \mathrm{~m}^{3} \leq V_{L} \leq 10^{13} \mathrm{~m}^{3}$. This behaviour of $p\left(V_{L}\right)$ over 17 orders of magnitude is in spite of local geomorphologic settings, triggering mechanisms, length of period and extent of the area covered by the datasets, presence or lack of water in the failed soils and rocks, and intensity of gravitational fields. We suggest that the self-similar behaviour of landslide volumes is controlled primarily by the geometry and abundance of the discontinuities in the soil and rock mass where landslides initiate. Differences in the scaling exponent of the density distributions reflect differences in the landslide types, with rock falls systematically exhibiting a steeper tail $(1.5 \leq \beta \leq 1.9)$ than slides $(1.1 \leq \beta \leq 1.4)$. The difference reflects a disparity in the mechanical behaviour of rock falls and slides.

Our results advance the understanding of the statistics of landslide volumes, and can contribute to the validation of physical (Katz and Aharonov, 2006) and computer (Hergarten and Neugebauer, 1998; Juanico et al., 2008) models of landslide sizes, to regional studies of landslide hazard (Guzzetti et al., 2003, 2004, 2005, 2006), and to the modelling of erosion and sediment fluxes in landslide dominated landscapes (Hovius et al., 1997; Stark and Hovius, 2001; Malamud et al., 2004b; Korup, 2006; Guzzetti et al., 2008, 2009). The research is also a starting point to establish a physically-based scale for landslide events, based on landslide volume (Malamud et al., 2004a; Guzzetti et al., 2009).

\section{Appendix A}

\section{The KDE script}

To determine the probability density of landslide volume, $p\left(V_{L}\right)$, the author MTB prepared a script for the $\mathrm{R}$ free software environment for statistical computing, release 2.6.2 (http://www.r-project.org/). The following are available for download through the journal Web site, and at the universal resource locator address http://geomorphology.irpi.cnr.it/tools/stat-ls/pdf-ls-vol:

(i) the script KDE_landslide_volumes.r, (ii) two example datasets Data_volume_m3_UmbriaMarche.txt, Data_volume_m3_BalzaTagliata.txt, (iii) a file with illustrative results Output.pdf. The two demonstrative datasets are provided as text files, and list datasets A and B in Table 2. The script can be customized to analyze different landslide volume data.

Acknowledgements. We are grateful to the colleagues that have provided individual landslide datasets. We thank two reviewers, for their constructive comments that improved the text substantially. Research supported by European Commission Project 12975 (NEST) Extreme Events: Causes and Consequences (E2-C2). MTB and MR were supported by grants provided by the Italian 
Space Agency (ASI MORFEO) and the Italian National Department for Civil Protection.

Edited by: B. Malamud

Reviewed by: two anonymous referees

\section{References}

Antonini, G., Ardizzone, F., Cardinali, M., Galli, M., Guzzetti, F., and Reichenbach, P.: Surface deposits and landslide inventory map of the area affected by the 1997 Umbria-Marche earthquakes, Boll. Soc. Geol. Ital., VS-1, 843-853, 2002.

Barnard, P. L., Owen, L. A., Sharma, M. C., and Finkel, R. C.: Natural and human-induced landsliding in the Garhwal Himalaya of northern India, Geomorphology, 40, 21-35, 2001.

Baum, R. L., Harp, E. L., and Hultman, W. A.: Map showing recent and historic landslide activity on coastal bluffs of Puget Sound between Shilshole Bay and Everett, Washington, US Geological Survey Miscellaneous Field Studies Map MF-2346, 2000.

Brardinoni, F. and Church, M.: Representing the landslide magnitude-frequency relation: Capilano River basin, British Columbia, Earth Surf. Proc. Land., 29(1), 115-124, 2004.

Cello, G. and Malamud, B. D. (Eds.): Fractal Analysis for Natural Hazards. Geological Society, London, Special Publications, 261, 172 pp., 2006.

Cruden, D. M. and Varnes, D. J.: Landslide types and processes, in: Landslides, Investigation and Mitigation, edited by: Turner, A. K. and Schuster, R. L., Transportation Research Board Special Report 247, Washington, D.C., 36-75, 1996.

Dai, F. C. and Lee, C. F.: Frequency-volume relation and prediction of rainfall-induced landslides, Eng. Geol., 59, 253-266, 2001.

Dussauge, C., Grasso, J. R., and Helmstetter, A.: Statistical analysis of rockfall volume distributions: implications for rockfall dynamics, J. Geophys. Res., 108(B6), 2286, doi:10.1029/2001JB000650, 2003.

Dussauge-Peisser, C., Helmstetter, A., Grasso, J.-R., Hantz, D., Desvarreux, P., Jeannin, M., and Giraud, A.: Probabilistic approach to rock fall hazard assessment: potential of historical data analysis, Nat. Hazards Earth Syst. Sci., 2, 15-26, 2002, http://www.nat-hazards-earth-syst-sci.net/2/15/2002/.

Dykes, A. P. and Warburton, J.: Characteristics of the Shetland Islands (UK) peat slides of 19 September 2003, Landslides, 5(2), 213-226, 2008.

Erismann, T. H. and Abele, G.: Dynamics of Rockslides and Rockfalls, Springer, 316 pp., 2001.

Fujii, Y.: Frequency distribution of landslides caused by heavy rainfall, J. Seismol. Soc. Japan, 22, 244-247, 1969.

Gardner, J. S.: Rockfall frequency and distribution in the Highwood Pass area, Canadian Rocky Mountain, Z. Geomorphol., 27(3), 311-324, 1983.

Gardner, J. S.: Rockfall: a geomorphic process in high mountain terrain, The Albertan Geogr., 6, 15-20, 1970.

Guzzetti, F., Ardizzone, F., Cardinali, M., Galli, M., and Reichenbach, P.: Distribution of landslides in the Upper Tiber River basin, Central Italy, Geomorphology, 96, 105-122, 2008.

Guzzetti, F., Ardizzone, F., Cardinali, M., Galli, M., Rossi, M., and Valigi, D.: Landslide volumes and landslide mobilization rates in Umbria, central Italy, Earth Planet. Sci. Lett., 279, 222-229, doi:10.1016/j.epsl.2009.01.005, 2009.
Guzzetti, F., Galli, M., Reichenbach, P., Ardizzone, F., and Cardinali, M.: Landslide hazard assessment in the Collazzone area, Umbria, Central Italy, Nat. Hazards Earth Syst. Sci., 6, 115-131, 2006, http://www.nat-hazards-earth-syst-sci.net/6/115/2006/.

Guzzetti, F., Malamud, B. D., Turcotte, D. L., and Reichenbach, P.: Power-law correlations of landslide areas in Central Italy, Earth Planet. Sci. Lett., 195, 169-183, 2002.

Guzzetti, F., Reichenbach, P., Cardinali, M., Galli, M., and Ardizzone, F.: Probabilistic landslide hazard assessment at the basin scale, Geomorphology, 72, 272-299, 2005.

Guzzetti, F., Reichenbach, P., and Ghigi, S.: Rockfall hazard and risk assessment in the Nera River Valley, Umbria Region, central Italy, Environ. Manage., 34(2), 191-208, 2004.

Guzzetti, F., Reichenbach, P., and Wieczorek, G. F.: Rockfall hazard and risk assessment in the Yosemite Valley, California, USA, Nat. Hazards Earth Syst. Sci., 3, 491-503, 2003, http://www.nat-hazards-earth-syst-sci.net/3/491/2003/.

Guzzetti, F. and Tonelli, G.: Information system on hydrological and geomorphological catastrophes in Italy (SICI): a tool for managing landslide and flood hazards, Nat. Hazards Earth Syst. Sci., 4, 213-232, 2004, http://www.nat-hazards-earth-syst-sci.net/4/213/2004/.

Hampton, M. A., Lee, H. L., and Locat, J.: Submarine landslides, Rev. Geophys., 34, 33-59, 1996.

Hayashi, J. N. and Self S.: A comparison of pyroclastic flow and debris avalanche mobility, J. Geophys. Res., 97, 9063-9071, 1992.

Hergarten, S. and Neugebauer, H. J.: Self-organized criticality in a landslide model, Geophys. Res. Lett., 25, 801-804, 1998.

Hovius, N., Stark, C. P., and Allen, P. A.: Sediment flux from a mountain belt derived by landslide mapping, Geology, 25, 231234, 1997.

Hungr, O., Evans, S. G., and Hazzard, J.: Magnitude and frequency of rock falls and rock slides along the main transportation corridors of southwestern British Columbia, Can. Geotech. J., 36(2), 224-238, 1999.

Issler, D., De Blasio, F. V., Elverhøi, A., Bryn, P., and Lien, R.: Scaling behaviour of clay-rich submarine debris flows, Mar. Petrol. Geol., 22(1-2), 187-194, 2005.

Iverson, R. M.: The physics of debris flows, Rev. Geophys., 35, 245-296, 1997.

Iverson, R. M., Schilling, S. P., and Vallance, J. W.: Objective delineation of lahar-inundated hazard zones, Geol. Soc. Am. Bull., 110, 972-984, 1998.

Juanico, D. E., Longjas, A., Batac, R., and Monterola, C.: Avalanche statistics of driven granular slides in a miniature mound, Geophys. Res. Lett., 35, L19403, doi:10.1029/2008GL035567, 2008.

Katz, O. and Aharonov, E.: Landslides in vibrating sand box: What controls types of slope failure and frequency magnitude relations?, Earth Planet. Sci. Lett., 247, 280-294, 2006.

Korup, O.: Rock-slope failure and the river long profile, Geology, 34(1), 45-48, 2006.

Larsen, M. C. and Torres-Sánchez, A. J.: Geographic relations of landslide distribution and assessment of landslide hazards in the Blanco, Cibuco and Coamo river basins, Puerto Rico, US Geological Survey Water Resources Investigation Report, 95-4029, 56 pp., 1996.

Larsen, M. C. and Torres-Sánchez, A. J.: The frequency and distribution of recent landslides in three montane tropical regions of 
Puerto Rico, Geomorphology, 24, 309-331, 1998.

Legros, F.: The mobility of long-runout landslides, Eng. Geol., 63, 301-331, 2002.

Malamud, B. D., Turcotte, D. L., Guzzetti, F., and Reichenbach, P.: Landslides, earthquakes and erosion, Earth Planet. Sci. Lett., 229, 45-59, 2004a.

Malamud, B. D., Turcotte, D. L., Guzzetti, F., and Reichenbach, P.: Landslide inventories and their statistical properties, Earth Surf. Proc. Land., 29, 687-711, 2004b.

Martin, Y., Rood, K., Schwab, J. W., and Church, M.: Sediment transfer by shallow landsliding in the Queen Charlotte Islands, British Columbia, Can. J. Earth Sci., 39(2), 189-205, 2002.

McEwen, A. S.: Mobility of large rock avalanches: evidence from Valles Marineris, Mars. Geology, 17, 1111-1114, 1989.

Newman, M. E. J.: Power laws, Pareto distributions and Zipf's law, Contemp. Phys., 46(5), 323-351, 2005.

Pelletier, J. D., Malamud, B. D., Blodgett, T., and Turcotte, D. L.: Scale-invariance of soil moisture variability and its implications for the frequency-size distribution of landslides, Eng. Geol., 48, 255-268, 1997.

Rice, R. M., Corbett, E. S., and Bailey, R. G.: Soil slips related to vegetation, topography, and soil in Southern California, Water Resour. Res., 5(3), 647-659, 1969.

Rice, R. M. and Foggin III, G. T.: Effects of high intensity storms on soil slippage on mountainous watersheds in Southern California, Water Resour. Res., 7(6), 1485-1496, 1971.

Scott, D. W.: Multivariate Density Estimation. Theory, Practice and Visualization, Wiley, New York, 1992.

Silverman, B. W.: Density Estimation. Chapman and Hall, London, 1986.
Simonett, D. S.: Landslide distribution and earthquakes in the Bewani and Torricelli Mountains, New Guinea, in: Landform Studies from Australia and New Guinea, edited by: Jennings, J. N. and Mabbutt, J. A., Cambridge University Press, Cambridge, 64 84, 1967.

Stark, C. P. and Hovius, N.: The characterization of landslide size distributions, Geophys. Res. Lett., 28, 1091-1094, 2001.

Turcotte, D. L.: Fractals and Chaos in Geology and Geophysics, 2nd edition, Cambridge University Press, New York, 398 pp., 1997.

Turcotte, D. L., Malamud, B. D., Guzzetti, F., and Reichenbach, P.: Self-organization, the cascade model and natural hazards, P. Natl. Acad. Sci., USA 99, Supp. 1, 2530-2537, 2002.

Van Den Eeckhaut, M., Poesen, J., Govers, G., Verstraeten, G., and Demoulin, A.: Characteristics of the size distribution of recent and historical landslides in a populated hilly region, Earth Planet. Sci. Lett., 256(3-4), 588-603, 2007.

Venables, W. N. and Ripley, B. D.: Modern Applied Statistics with S, Springer, New York, 2002.

Whalley, W. B., Douglas, G. R., and Jónsonn, A.: The magnitude and frequency of large rockslides in Iceland in the postglacial, Geogr. Ann. A, 65A(1-2), 99-110, 1983.

White, E. P., Enquist, B. J., and Green, J. L.: On estimating the exponent of power-law frequency distributions, Ecology, 89(4), 905-912, 2008.

Whitehouse, I. E. and Griffiths, G. A.: Frequency and hazard of large rock avalanches in the central Southern Alps, New Zealand, Geology, 11, 331-334, 1983.

Wieczorek, G. F., Snyder, J. B., Alger, C. S., and Isaacson, K. A. Rock falls in Yosemite Valley, California, US Geological Survey Open-File Report 92-387, 38 pp., 1992. 